\title{
Matrix Gla protein is involved in elastic fiber calcification in the dermis of pseudoxanthoma elasticum patients
}

\author{
Dealba Gheduzzi ${ }^{1, *}$, Federica Boraldi ${ }^{1, *}$, Giulia Annovi ${ }^{1}$, Chiara Paolinelli DeVincenzi ${ }^{1}$, Leon J Schurgers ${ }^{2}$, \\ Cees Vermeer ${ }^{2}$, Daniela Quaglino ${ }^{1}$ and Ivonne Pasquali Ronchetti ${ }^{1}$
}

Mature MGP (Matrix $\gamma$-carboxyglutamic acid protein) is known to inhibit soft connective tissues calcification. We investigated its possible involvement in pseudoxanthoma elasticum (PXE), a genetic disorder whose clinical manifestations are due to mineralization of elastic fibers. PXE patients have lower serum concentration of total MGP compared to controls $(P<0.001)$. Antibodies specific for the noncarboxylated (Glu-MGP) and for the $\gamma$-carboxylated (Gla-MGP) forms of MGP were assayed on ultrathin sections of dermis from controls and PXE patients. Normal elastic fibers in controls and patients were slightly positive for both forms of MGP, whereas Gla-MGP was more abundant within control's than within patient's elastic fibers $(P<0.001)$. In patients' calcified elastic fibers, Glu-MGP intensively colocalized with mineral precipitates, whereas Gla-MGP precisely localized at the mineralization front. Data suggest that MGP is present within elastic fibers and is associated with calcification of dermal elastic fibers in PXE. To investigate whether local cells produce MGP, dermal fibroblasts were cultured in vitro and MGP was assayed at mRNA and protein levels. In spite of very similar MGP mRNA expression, cells from PXE patients produced 30\% less of Gla-MGP compared to controls. Data were confirmed by immunocytochemistry on ultrathin sections. Normal fibroblasts in vitro were positive for both forms of MGP. PXE fibroblasts were positive for Glu-MGP and only barely positive for Gla-MGP $(P<0.001)$. In conclusion, MGP is involved in elastic fiber calcification in PXE. The lower ratio of Gla-MGP over Glu-MGP in pathological fibroblasts compared to controls suggests these cells may play an important role in the ectopic calcification in PXE.

Laboratory Investigation (2007) 87, 998-1008; doi:10.1038/labinvest.3700667; published online 27 August 2007

KEYWORDS: calcification; dermal fibroblast; elastic fiber; human skin; MGP; pseudoxanthoma elasticum

The high concentration of calcium and phosphate in the extracellular space would lead to tissue calcification unless efficiently inhibited by a series of proteins and glycoproteins that have been found to operate in soft connective tissues to prevent calcium precipitation. ${ }^{1}$

Great attention has been recently paid to fetuin, which accumulates in the mineralized matrix of bone where it modulates apatite formation. ${ }^{2-4}$ It also circulates in serum where it probably inhibits mineral precipitation due to the acidic amino-acid residues of its cystatin-like domain. ${ }^{4,5}$ Recently, a significant decrease in fetuin was measured in the serum of patients with pseudoxanthoma elasticum (PXE), ${ }^{6}$ a genetic disorder characterized by mineralization of elastic fibers, ${ }^{7-9}$ and it has been suggested that fetuin could have been removed from serum and 'bound to the mineral deposits. ${ }^{5,10}$
Another protein involved in inhibition of calcium precipitation in soft connective tissues is matrix Gla protein (MGP), a $10-\mathrm{kDa}$ secreted protein containing 5-glutamic acid residues that must be $\gamma$-carboxylated by a vitamin $\mathrm{K}$ dependent $\gamma$-carboxylase in order to acquire calcium-binding properties. ${ }^{11,12}$ MGP-deficient mice manifest extensive calcification of the aorta and articular cartilage, ${ }^{12}$ similar to what has been observed in Keutel syndrome, which is due to mutations in the human MGP gene. ${ }^{13,14}$

Several in vitro and in vivo studies have shown that MGP is expressed by many peripheral cell types, including fibroblasts and smooth muscle cells. ${ }^{15-18}$ In an in vitro model of vascular calcification, the expression of MGP mRNA by smooth muscle cells was inversely correlated with mineral formation. ${ }^{19}$ Overexpression of MGP was shown to inhibit normal chondrocyte and cartilage mineralization, ${ }^{20}$ whereas inhibi-

\footnotetext{
${ }^{1}$ Department of Biomedical Sciences, University of Modena and Reggio Emilia, Modena, Italy and ${ }^{2}$ Department of Biochemistry, University of Maastricht, Maastricht, The Netherlands

Correspondence: Professor IP Ronchetti, PhD, Department of Biomedical Sciences, Via Campi, 287, Modena 41100, Italy. E-mail: ronchetti.ivonne@unimore.it

*These authors contributed equally to this work.

Received 20 February 2007; revised 12 July 2007; accepted 17 July 2007
} 
tion of MGP maturation by warfarin treatment induced calcification of cartilage and aorta, both in animals ${ }^{21-23}$ and humans. ${ }^{24,25}$ Moreover, in aortas, mineralization induced by warfarin was observed limited to elastic fibers, in the absence of necrotic material, and therefore attributable to an active process. ${ }^{22,26}$ Therefore, defects in MGP carboxylation seems to be associated with elastin mineralization. In a recent paper, dermal elastic fiber calcification has been extensively described in patients affected by coagulation disorders due to a genetic defect in vitamin $\mathrm{K}$ recycling with consequent deficient protein $\gamma$-carboxylation. ${ }^{27}$

In the present study, we investigated on the possible involvement of MGP on elastic fiber calcification in PXE, by measuring MGP serum level and its distribution in the dermis of controls and PXE patients. Moreover, since fibroblasts are responsible for the homeostatic control of connective tissues, we investigated whether dermal fibroblasts isolated from patients had normal efficiency in the expression and maturation of MGP. The following parameters were investigated: (i) the serum MGP level in PXE patients compared to controls. (ii) the relative amount and immunolocalization of both $\gamma$-carboxylated and noncarboxylated forms of MGP in the dermis of controls and PXE patients, mainly focusing on elastic fibers; (iii) the expression and immunolocalization of both Gla-MGP and GluMGP in human dermal fibroblasts cultured in vitro and isolated from normal subjects and PXE patients. Data indicate a deficiency in the homeostatic control of MGP maturation in PXE dermal fibroblasts.

\section{MATERIALS AND METHODS}

\section{Blood, Serum, and Plasma Collection}

The protocol for the present study was approved by the Medical Ethical Committee of the University of Modena and Reggio Emilia. Healthy subjects were recruited from volunteers; PXE subjects were from the collection present in our reference Center for the Diagnosis of PXE. Patients and controls were of comparable age (ranging from 18 to 65 years). Blood was taken by venipuncture from 30 controls (from 21 to 65 years, mean age $38 \pm 14$ years; 4 men and 36 women) and from 30 PXE patients (from 13 to 64 years; mean age $41 \pm 14$ years; 4 men and 36 women), collected in serum tubes, stored for $1 \mathrm{~h}$ at room temperature and centrifuged at $3000 \mathrm{~g}$ for $10 \mathrm{~min}$. Aliquots of serum were frozen and stored at $-80^{\circ} \mathrm{C}$ until used. For plasma, blood from 15 women affected by PXE was collected into $\mathrm{Na}$ citrate-containing tubes, centrifuged at $3500 \mathrm{~g}$ for $10 \mathrm{~min}$ at $4^{\circ} \mathrm{C}$. Aliquots of plasma-citrate were stored at $-85^{\circ} \mathrm{C}$ until used. As controls, normal pooled laboratory plasma was used.

\section{Skin Biopsies and Cell Culture}

After informed consent, skin biopsies were taken under local anesthesia from the neck or from the axilla of six PXE patients and six normal subjects who underwent surgery and did not show any clinical sign of connective tissue alterations.
All PXE patients had severe clinical manifestations, such as coalescent skin papules on the posterior and lateral neck, in the axillae and groin, skin laxity in flexural areas. They were also diagnosed by ultrastructural analysis of skin biopsies and by identification of ABCC6 mutations on both alleles. ${ }^{28}$ Fibroblast cultures were established and maintained according to Quaglino et al. ${ }^{29}$ Briefly, skin biopsies were fragmented and cells were grown as monolayer in $75 \mathrm{~cm}$ flasks (Nunc, Roskilde, Denmark) in Dulbecco's modified Eagle's medium (DMEM) containing 10\% fetal bovine serum (FBS) and used between the third and the tenth passage in vitro. Control and PXE cells were used at the same passage within each experiment.

\section{Protein Preparation}

Fibroblasts were plated in $75 \mathrm{~cm}^{2}$ flasks at a density of $8 \times 10^{5}$ cells in $15 \mathrm{ml}$ DMEM with $10 \%$ FBS. After 7 days from seeding, cells were removed from the culture flasks with $0.25 \%$ trypsin-EDTA in phosphate-buffered saline (PBS) for $10 \mathrm{~min}$ at $37^{\circ} \mathrm{C}$. Trypsin was blocked by addition of DMEM plus $10 \%$ FBS. Cells were centrifuged for $5 \mathrm{~min}$ at 1000 r.p.m. at $4^{\circ} \mathrm{C}$, washed with cold PBS, centrifuged again and then suspended in isotonic buffer containing $25 \mathrm{mM}$ imidazole, $250 \mathrm{mM}$ sucrose, $10 \mu \mathrm{g} / \mathrm{ml}$ Sigma protease inhibitor mixture and $1 \mathrm{mM} \mathrm{NaF}, \mathrm{pH}$ 7.5. Cells were sonicated on ice in a Sonifier B-12 (Branson Sonic Power Company, Danbury, Connecticut, USA) with 20 pulses of $2 \mathrm{~s}$ each. The sonicate was centrifuged at $10000 \mathrm{~g}$ for $10 \mathrm{~min}$ to remove cell debris. The membrane-enriched fraction was obtained by centrifuging the supernatant at $229000 \mathrm{~g}$ for $60 \mathrm{~min}$ in a Type $50-\mathrm{Ti}$ rotor (Beckman Instruments, Fullerton, CA, USA) and stored frozen at $-85^{\circ} \mathrm{C}$ until used. Prior to 2D-PAGE, membrane proteins were dissolved in $250 \mathrm{mM}$ phosphate, $0.5 \mathrm{M} \mathrm{KCl}$, $20 \%$ glycerol, and $0.75 \%$ CHAPS, $\mathrm{pH} 7.85$, containing $10 \mu \mathrm{l} / \mathrm{ml}$ Sigma protease inhibitor mixture and subsequently precipitated with the ProteoExtract Protein Precipitation Kit (Calbiochem, Darmstadt, Germany) according to the instruction. Proteins were harvested frozen at $-20^{\circ} \mathrm{C}$.

\section{Electrophoresis}

Proteins extracted from a pool of fibroblasts derived from six patients and six controls were used for each assay. Proteins were dissolved in $8 \mathrm{M}$ urea, 2\% CHAPS, $65 \mathrm{mM}$ dithioerythritol, 2\% pH 3-10 ampholyte (GE HealthCare, UK), and trace of bromphenol blue and were then applied onto Immobiline $\mathrm{pH}$ 3-10 nonlinear DryStrips $(7 \mathrm{~cm}$ long, GE HealthCare). Isoelectric focusing was performed on an IPGphor system (GE HealthCare) at $16^{\circ} \mathrm{C}$ according to the instruction manual. Immobilized $\mathrm{pH}$ gradient strips were reduced ( $2 \%$ dithioerythritol), alkylated $(2.5 \%$ iodoacetamide) in equilibration buffer ( $6 \mathrm{M}$ urea, $50 \mathrm{mM}$ Tris- $\mathrm{HCl}, \mathrm{pH}$ 6.8, $30 \%$ glycerol, $2 \%$ SDS) and then loaded onto vertical SDS-PAGE gel (15\%). The second dimension was run using an electrophoresis Unit (Bio-Rad). Gels were stained with ammoniacal silver nitrate. 


\section{Western Blotting}

It was carried out after transfer of proteins to nitrocellulose membranes, applying a $200 \mathrm{~mA}$ constant current. Membranes were washed with TTBS $(50 \mathrm{mM}$ Tris, $150 \mathrm{mM}$ $\mathrm{NaCl}, \mathrm{pH} 7.5$, plus $0.1 \%$ Tween 20 ) and blocked with $3 \%$ BSA in TTBS. Nitrocellulose films were incubated with primary antibodies (mouse anti- $\gamma$-carboxylated-MGP or mouse antinon-carboxylated-MGP) diluted 1:10000 in TTBS plus $1 \%$ BSA. After washes with TTBS, the incubation with the secondary antibody was performed by using anti-mouse IgG conjugated with horseradish peroxidase (GE HealthCare) diluted 1:20000 in TTBS and 1\% BSA and the immunoreaction was revealed by using the SuperSignal West Pico Chemiluminescent Substrate (Pierce) and normalized to $\beta$-actin.

\section{Quantitative Real-Time RT-PCR}

Total RNA was isolated from cells using the RNeasy Protect cells Mini kit (Qiagen, Valencia, CA, USA). Quality and quantity of RNA were checked by spectrophotometer and agarose gel. Then $3 \mu \mathrm{g}$ of total RNA was reverse transcribed using Superscript III (Invitrogen) and Oligo $\mathrm{dT}_{18}$ primers (Invitrogen) according to the manufacturer's instruction and conversion was confirmed by a PCR with CLK2 primers. A negative control was carried out to ensure the absence of DNA contamination. A $10 \times$ diluted cDNA sample was further amplified on an iCycler (BioRad) using SYBR $^{\circledR}$ GreenER ${ }^{\text {TM }}$ PCR SuperMix (Invitrogen), according to the manufacturer's instruction. Primers for conducting real-time RT-PCR are shown in Table 1 and were designed using Universal ProbeLibrary version 2.35 for human (www.rocheapplied-science.com) and were synthesized by Invitrogen. All RT-PCR analyses were carried out in triplicate. The thermal cycling parameters were set to $50^{\circ} \mathrm{C}$ for $2 \mathrm{~min}, 95^{\circ} \mathrm{C}$ for 3 min, 45 cycles of $95^{\circ} \mathrm{C}$ for $30 \mathrm{~s}$, an annealing temperature of $60^{\circ} \mathrm{C}$ for $30 \mathrm{~s}$ and $72^{\circ} \mathrm{C}$ for $30 \mathrm{~s}$, followed by melting curve analysis with a temperature ranging from 95 to $55^{\circ} \mathrm{C}$. Gene expression in each sample was normalized to the expression of an housekeeping gene (CLK2) and compared with control samples, using the $2^{-\Delta \Delta \mathrm{Ct}}$ method. ${ }^{30}$

\section{Table 1 Primers used for real-time RT-PCR}

Length Position Tm \% GC Sequence

$\begin{array}{llllll}\text { CLK2 } & & & & & \\ \text { Sense } & 20 & 667-686 & 59 & 50 & \text { GGACATTAAGCCGCTCATCT } \\ \text { Antisense } & 21 & 706-726 & 59 & 50 & \text { CGTCGTCCTCTACACTCTTGG }\end{array}$

MGP

$\begin{array}{llllll}\text { Sense } & 21 & 135-155 & 59 & 52 & \text { CCGCCTTAGCGGTAGTAACTT } \\ \text { Antisense } & 20 & 227-246 & 59 & 52 & \text { TGCTGAGGGGATATGAAGGT }\end{array}$

\section{Immunocytochemistry}

Skin biopsies and cultured fibroblasts were processed for electron microscopy. Briefly, small fragments of skin biopsies or fibroblasts scraped from the substrate and centrifuged to form a pellet were immediately fixed in $2.5 \%$ paraformaldehyde in Tyrode's saline, $\mathrm{pH} 7.2$, for $16-20 \mathrm{~h}$ at $4^{\circ} \mathrm{C}$, followed by fixation in $0.5 \%$ osmium tetroxide (Fluka AG Chem) in the same buffer for $60 \mathrm{~min}$ at room temperature, dehydration in ethanol and propylene oxide and embedding in Spurr resin (Polysciences Inc., Warrington, PA, USA). Ultrathin sections were collected on nickel grids and processed for immunocytochemistry as already described. ${ }^{31}$ Unspecific epitopes were neutralized by incubating sections on $0.5 \%$ bovine serum albumin in buffer. Monoclonal antibodies towards the noncarboxylated species of MGP and towards the $\gamma$-carboxylated form of $\mathrm{MGP}^{32,33}$ were used in parallel in all experiments where normal and PXE samples had to be compared. The immunoreactions were revealed by secondary antibodies conjugated with $10 \mathrm{~nm}$ gold particles (EY Laboratories, San Mateo, CA, USA). Controls for the immunoreactions were performed by omitting the primary antibody or by incubating the sections with nonimmune sera instead of the primary antibody. Sections were then stained with uranyl acetate and lead citrate and observed by transmission electron microscopy (Jeol, EM1200, Tokyo, Japan).

\section{Immunoassay for Serum MGP}

Serum MGP was assayed by using the test kit from Biomedica (Vienna, Austria). It is a competitive enzyme-linked immunosorbent assay (ELISA) in which microwell plates are coated with mouse monoclonal antibodies raised against human MGP. The protocol described by Schurgers et $a l^{32,33}$ has been applied.

\section{Coagulation Factors}

The procoagulant activity of prothrombin (FIIc) and factor VIIc were measured in a coagulometer (ACL 300 Research; Instrumentation Laboratory, Milan, Italy) using Thromborel $\mathrm{S}$ and human coagulation factor II- and VII-deficient plasma (Behringwerke AG, Marburg, Germany). All values were expressed as a percentage of values obtained for pooled normal plasma.

\section{Statistical Analysis}

The intensity of immunostaining was evaluated by counting the number of gold particles present in 20 random fields on ultrathin sections of dermal elastic fibers or of cytoplasm of cultured dermal fibroblasts by applying a $1 \mu \mathrm{m}^{2}$ mask on images obtained at the same magnification $(\times 20000)$. Data were compared by Student's $t$-test with significance at $P<0.05$. The immunoreactivity of the two antibodies was different, therefore only intra-antibody comparison was carried out. 


\section{RESULTS}

\section{MGP Content in Serum of PXE Patients}

Previous studies showed that, in humans, there are no significant differences in the MGP levels between genders and no significant variations with age. ${ }^{32,33}$ In the present study, circulating MGP level was measured in the serum of 30 controls and of 30 PXE patients (see Materials and Methods). Figure 1 illustrates that the amount of MGP was statistically lower in patients $(5.16 \pm 1.07 \mathrm{nM} / \mathrm{ml})$ compared to controls $(7.26 \pm 1.24 \mathrm{nM} / \mathrm{ml})(P<0.001)$. Unfortunately, the method could not discriminate between the $\gamma$-carboxylated and the noncarboxylated forms of MGP.

\section{Immunolocalization of MGP in the Human Dermis}

In order to investigate whether MGP is involved in elastic fiber calcification in PXE, ultrathin sections of skin biopsies from normal subjects and from patients affected by PXE were immunostained in parallel by using antibodies specific for the noncarboxylated (Glu-MGP) and for the $\gamma$-carboxylated (Gla-MGP) forms of MGP. ${ }^{32,33}$

In normal skin, fibroblasts were almost negative for Glu-MGP, whereas they were slightly positive for Gla-MGP (not shown). In the dermis of PXE patients, fibroblasts were almost negative for both forms of MGP (not shown).

All components of the extracellular matrix, apart from elastic fibers, were always negative for both types of antibodies in all samples of both controls and patients. In contrast, elastic fibers were always positive for MGP. In particular, Glu-MGP was equally present within control's elastic fibers (Figure 2a) and within noncalcified elastic fibers in the dermis of PXE patients (Figure 2b). By contrast, GlaMGP was always present within control's elastic fibers (Figure 3a), whereas it was almost absent from noncalcified PXE elastic fibers (Figure $3 \mathrm{~b}$ ). The number of gold particles per unit surface area of sectioned elastic fibers and the significance of data are reported in Figures 2 and 3. As already pointed out in the Materials and Method section, the two

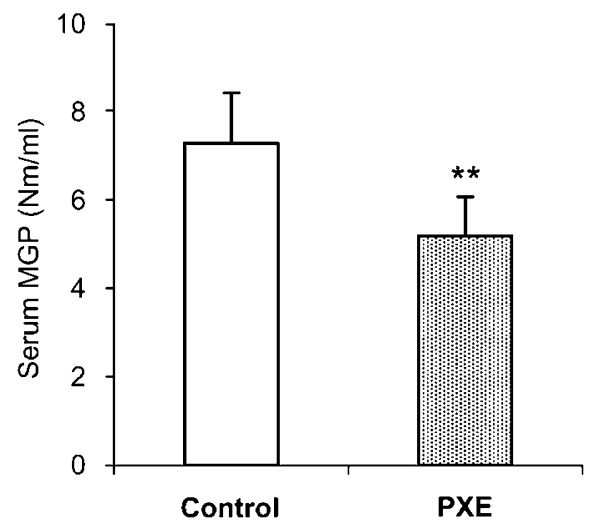

Figure 1 Total MGP measured in the serum of 30 controls and of 30 PXE patients of comparable age. The level of MGP was significantly higher in the serum of normal subjects compared to patients $(P<0.001)$. antibodies had different reactivity and their immunoreactions could not be compared. Therefore, comparison could only be made between control and pathological samples treated with the same antibody under identical experimental conditions. Data clearly show that Gla-MGP was almost absent from elastic fibers in patients.

As already described in several reports, calcification of elastic fibers in the dermis of PXE can assume different structural forms, which are often present in distinct regions of the same fiber. ${ }^{8}$ The two main forms are represented in Figure 4. One of them consists of electron-opaque polymorphic masses of calcified material deforming and fracturing the elastic fibers (Figure $4 \mathrm{a}$, arrows). The second form is characterized by dispersed small-calcified spots occupying the center of fibers (Figure $4 \mathrm{a}$ and $\mathrm{b}$, asterisk) and separated from the surrounding apparently normal elastin by an electron opaque ring made of needle-shaped crystals (Figure $4 \mathrm{~b}$, inset).

The two antibodies tested reacted in a completely different manner on these two different regions. The antibody that recognizes Glu-MGP strongly reacted with the polymorphous calcified areas and with the finely dispersed calcified core of elastic fibers (Figure 4c, asterisks). By contrast, the antibody towards Gla-MGP was absent from these regions and was only and precisely localized at the calcification front separating the central mineralized core from the surrounding apparently normal elastin (Figure 4d, arrows).

\section{MGP by In Vitro Dermal Fibroblasts}

Since peripheral cells, namely fibroblasts and smooth muscle cells, are the major producers of MGP in vivo, ${ }^{15,17,34}$ we wanted to analyse whether dermal fibroblasts might be involved in MGP expression and maturation. Dermal fibroblasts were isolated from skin biopsies of both controls and PXE patients and were analysed for the expression of MGP. The expression of MGP mRNA was similar in controls and in PXE fibroblasts, differences being statistically not significant (Figure 5).

When measured at protein level, as illustrated in Figure 6, the total amount of MGP in PXE cells was about 25\% less than that found in control fibroblasts $(P<0.05)$. As specified in the Materials and Method section, analyses were performed on a pool of cell membranes from fibroblasts of six patients and six controls in each experiment, and experiments were carried out in triplicate. Therefore, the subfractionation method employed should circumvent the evaluation of MGP eventually taken up by cells from the medium and accumulating within the cytoplasm.

Data on the relative amounts of Glu-MGP (a) and Gla-MGP (b), identified by specific antibodies and normalized to the $\beta$-actin content, are shown in Figure 6 . The amount of Glu-MGP was very similar in both control (34\%) and PXE (32\%) fibroblasts. By contrast, the relative amount of Gla-MGP was $66 \%$ in controls, whereas it was around $43 \%$ in PXE cells, and the ratio between Gla-MGP to Glu-MGP 


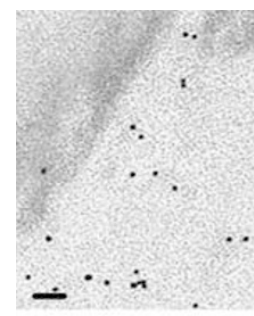

a

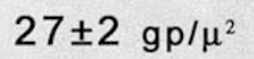

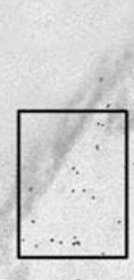
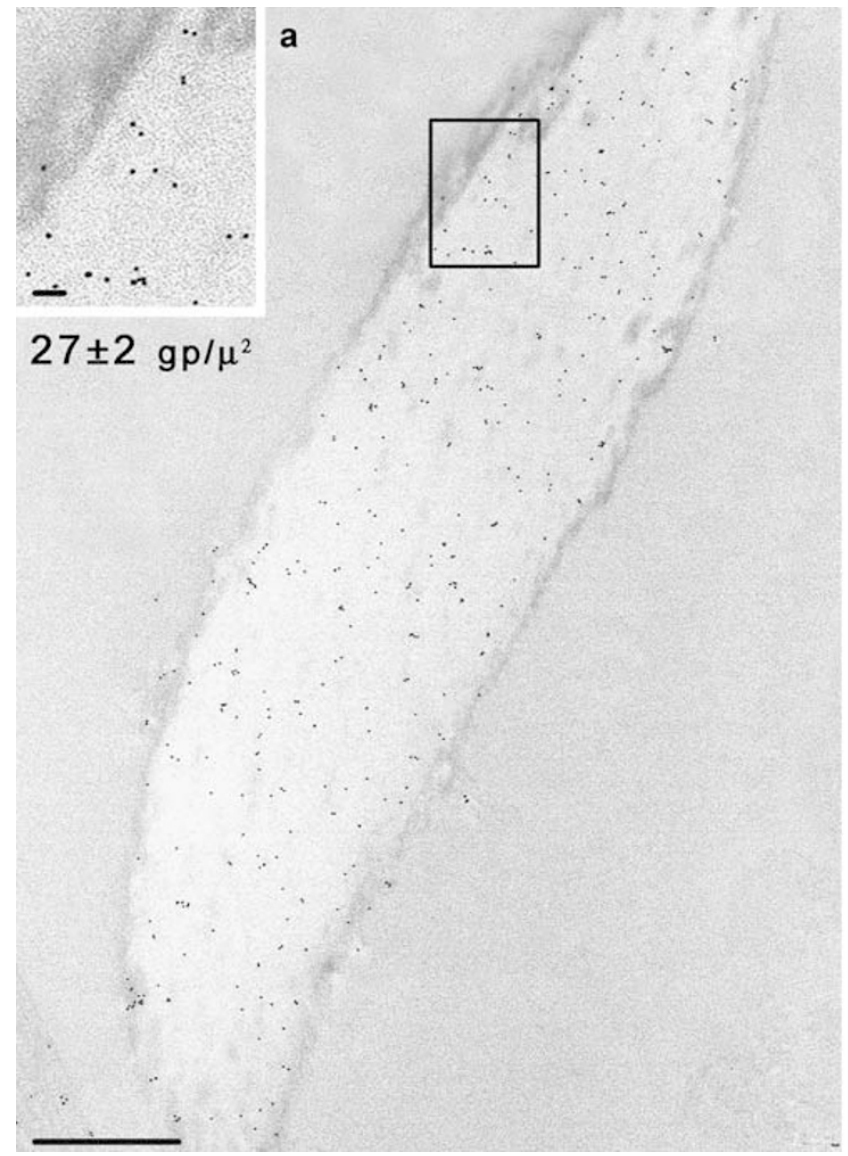

Figure 2 Immunolocalization of noncarboxylated MGP (Glu-MGP) on elastic fibers of the normal human dermis (a) and on the nonmineralized dermal elastic fibers of PXE patients (b). The number of gold particles (gp) per unit area of elastic fibers was almost the same in the two conditions. Bar: (a) and (b) $1 \mu \mathrm{m}$; insets $0.1 \mu \mathrm{m}$.

was more than $30 \%$ lower in PXE (1.34) compared to controls $(1.94)(P<0.01)$ (Figure $6 c$ ).

\section{Immunolocalization of MGP on In Vitro Dermal Fibroblasts}

In vitro dermal fibroblasts were positive for MGP, as shown by the immunoelectron-microscopy approach applied to thin sections of cultured fibroblasts. The amount and distribution of Glu-MGP were scarce and almost identical in control (a) and PXE (b) fibroblasts (Figure 7). By contrast, Figure 8 illustrates that the immunoreaction towards Gla-MGP was much stronger in control (a) compared to PXE (b) fibroblasts. The number of gold particles per square unit of cytoplasm measured on random fields was $30 \pm 11 / \mu^{2}$ in controls and $12 \pm 4 / \mu^{2}$ in PXE cells $(P<0.001)$. Moreover, as expected from data of the literature, ${ }^{32}$ the immunoreaction for Gla-MGP was precisely and almost exclusively localized on membranes of the endoplasmic reticulum in both control and PXE fibroblasts.

\section{Coagulation Factor}

Measurements of coagulation factors II and VII in the plasma of PXE patients did not reveal any significant difference

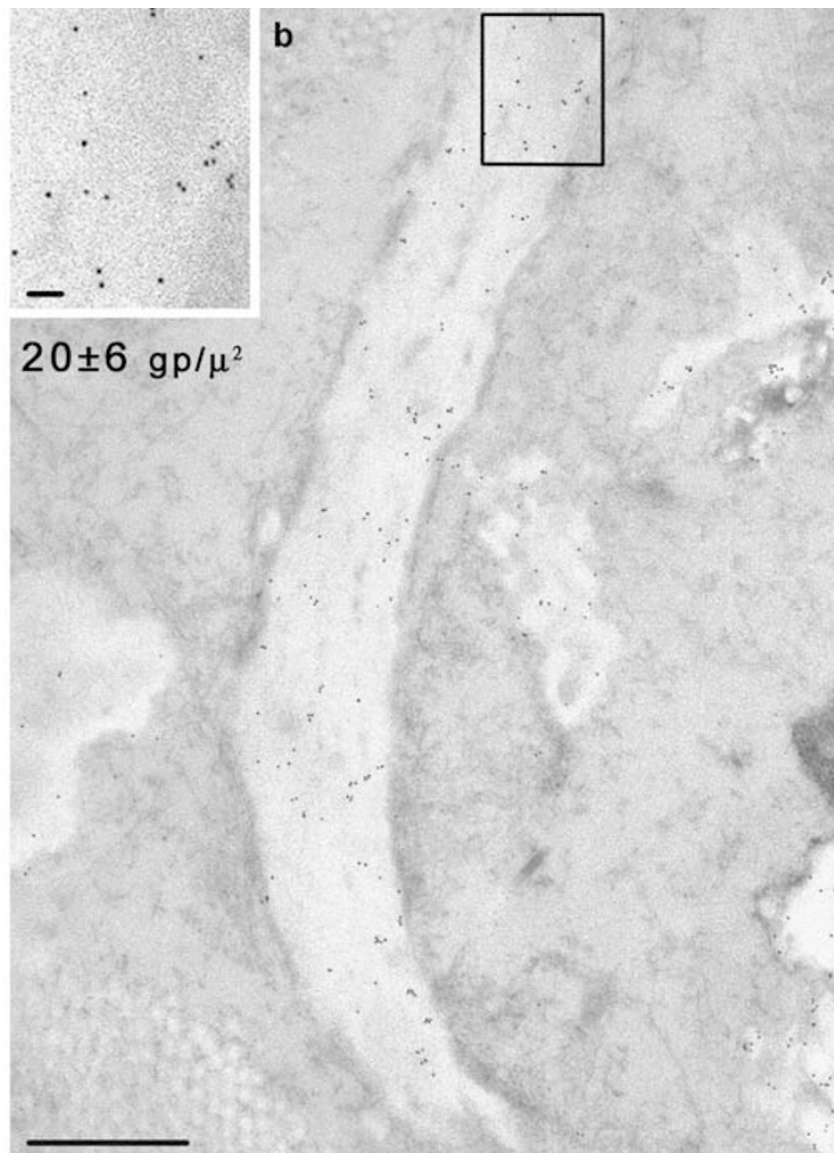

between patients and controls. Values for coagulation factors II and VII were only 3 and 7\% higher in PXE patients compared to controls (data not shown).

\section{DISCUSSION}

Relevant findings of this work are that human dermal fibroblasts express and produce MGP, and that MGP is present within normal elastic fibers in the human dermis.

Owing to the well-recognized role of MGP in preventing mineralization of soft connective tissues ${ }^{11,12,15,19,20}$ and the propensity of elastin per sé to accumulate calcium, ${ }^{35}$ the presence of MGP within normal elastic fibers would suggest that this protein may have a role in preventing elastic fiber calcification. Strategic location of $\gamma$-carboxylated MGP within elastic fibers may protect those unique structures against mineralization. Elastic fibers of PXE patients that contain only the noncarboxylated immature MGP are not protected from sequestration of calcium from the serum. Moreover, MGP is involved in PXE calcification, being immature noncarboxylated MGP (Glu-MGP) associated with mineral precipitates and $\gamma$-carboxylated MGP (Gla-MGP) associated with the calcification front. These data suggest once more the different and opposite 

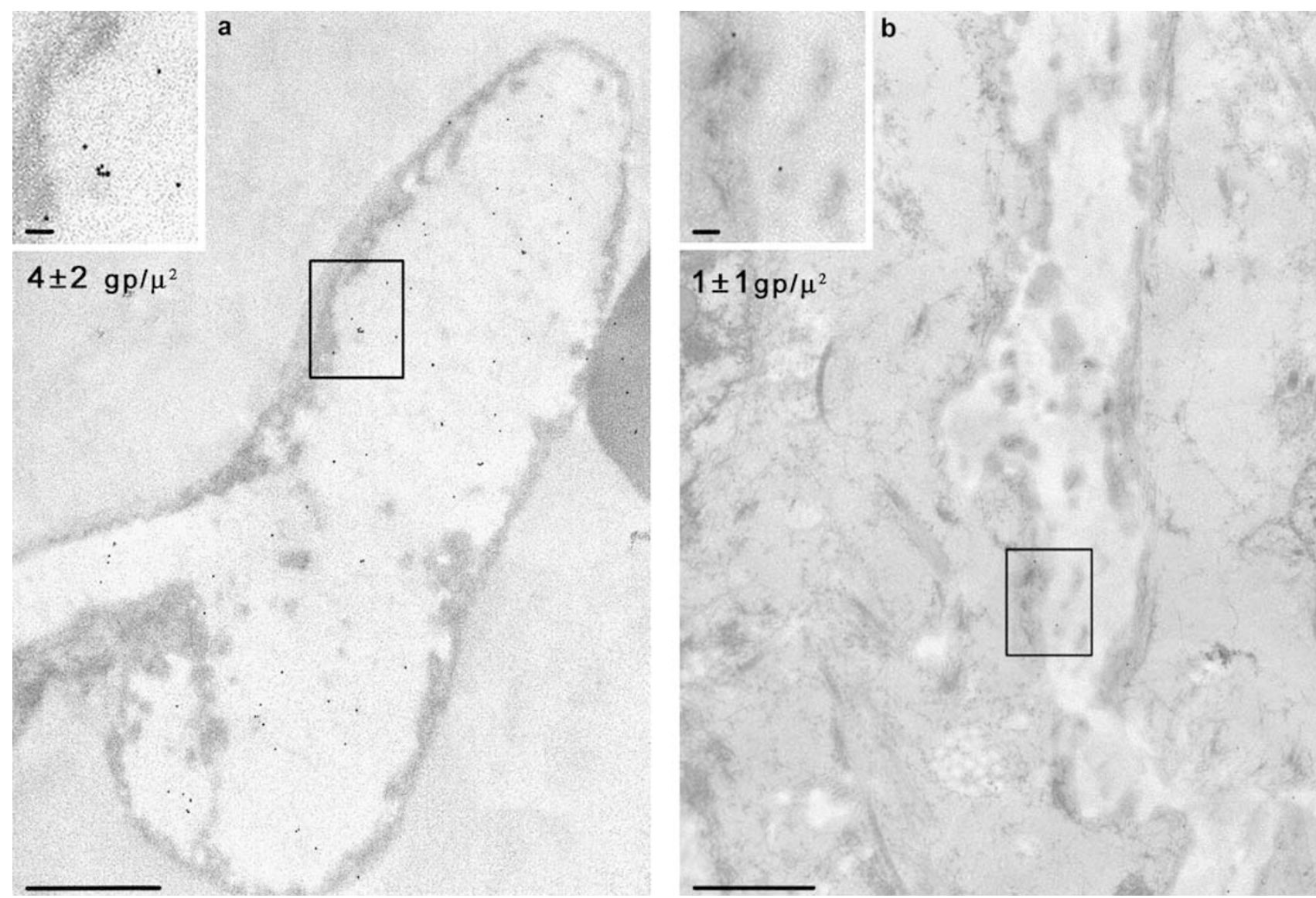

Figure 3 Immunolocalization of $\gamma$-carboxylated MGP (Gla-MGP) on elastic fibers of the normal human dermis (a) and the nonmineralized dermal elastic fibers of PXE patients (b). The number of gold particles (gp) per unit area of elastic fiber was significantly higher in control compared with PXE $(P<0.001)$. Bar: (a) and (b) $1 \mu \mathrm{m}$; insets $0.1 \mu \mathrm{m}$.

role of the two forms of MGP in favouring/preventing calcium precipitation, respectively. Finally, MGP content, and in particular the ratio between Gla-MGP to Glu-MGP, could be taken as marker for elastic fiber calcification in PXE patients.

In the normal dermis, elastic fibers were immunologically positive for both Glu-MGP and Gla-MGP. By contrast, the noncalcified elastic fibers in PXE patients were almost negative for Gla-MGP. Therefore, elastic fibers of PXE patients would seem less protected from calcium precipitation due to their low content of the active $\gamma$-carboxylated form of the protein.

These data may explain findings by Gordon $e t a l^{36}$ who found that fragments of skin from PXE patients were able to accumulate more calcium compared to normal skin when incubated in a calcium-containing medium.

The different role of Glu- and Gla-MGP on the mineralization process of elastic fibers was shown by the different localization of the antibodies specific for the two forms of MGP even within the same elastic fiber. Glu-MGP was always and abundantly present in the areas of either bulky or spotty mineralization. By contrast, Gla-MGP was only and precisely localized at the thin frontline separating the central mineralized core from the surrounding apparently normal elastin. These data are in agreement with those obtained by light microscopy on human aortas in the early phase of atherosclerosis and in Monckeberg's sclerosis where the Glu-MGP has been observed to colocalize with calcification, whereas Gla-MGP has been found around elastic fibers. ${ }^{32}$ In that report, the low resolution of the technique did not allow the precise localization of the $\gamma$-carboxylated form of MGP. ${ }^{32}$ By considering the inhibitory role on calcification of mature $\gamma$-carboxylated MGP and that calcification seems to progress from the center of elastic fibers towards their periphery, the present data suggest that mature calcium-binding MGP (Gla-MGP) would arrest calcification at these peculiar sites. By contrast, immature Glu-MGP was always associated with bulky mineral precipitates where it might favor calcification. Similar to what is suggested for fetuin, ${ }^{5,10}$ it cannot be excluded that immature MGP is captured during calcification.

It has been already demonstrated that MGP is synthesized by numerous cell types, including smooth muscle cells, ${ }^{17,19,34,37}$ pneumocytes ${ }^{15,18}$ and chondrocytes. ${ }^{20,38}$ 

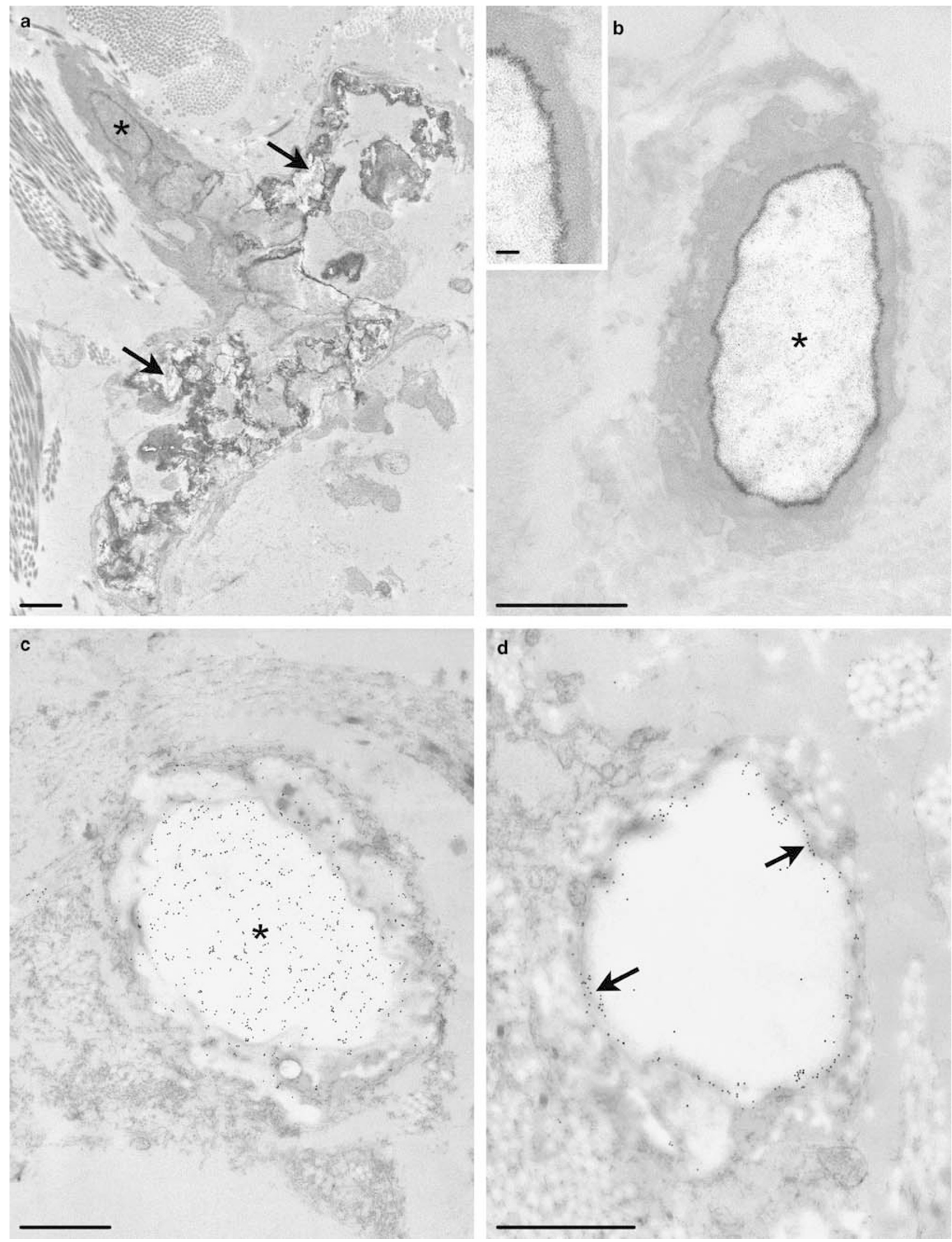
We wanted to verify whether dermal fibroblasts express MGP and whether they may be responsible for the low amount of the $\gamma$-carboxylated form of MGP within elastic fibers in the dermis of patients. Therefore, in vitro dermal fibroblasts from normal subjects and from patients affected by PXE, bearing identified ABCC6 mutations, ${ }^{28}$ were assayed and compared for MGP expression and maturation. The amount of the MGP protein was measured on cell membrane extracts in order to look for proteins actually belonging to the cells and not taken up from the medium. Data show that dermal fibroblasts express MGP in either the $\gamma$-carboxylated and the noncarboxylated forms. However, although the mRNA levels were very similar in control and PXE cells, the amount of protein, and in particular of the mature $\gamma$-carboxylated form of MGP, was significantly lower in PXE cells compared to controls $(P<0.01)$. Therefore, the data might support the hypothesis of a deficient posttranscriptional maturation of MGP by PXE fibroblasts.

Data obtained by immunoblotting were in perfect agreement with those by immunoelectron microscopy on thin sections of fibroblasts, where control cells were positive for Gla-MGP, whereas PXE fibroblasts were almost negative for the same antibodies.

The lower expression of $\gamma$-carboxylated MGP by PXE fibroblasts suggests that these cells may play an important role in calcification of dermal elastic fibers in PXE.

Total serum MGP content was lower in PXE patients compared to controls $(P<0.001)$. Unfortunately, the method did not allow to distinguish between the noncarboxylated and the $\gamma$-carboxylated forms of MGP. Recently, a reduced amount of fetuin, another serum protein involved in the inhibition of ectopic calcification, has been measured in the

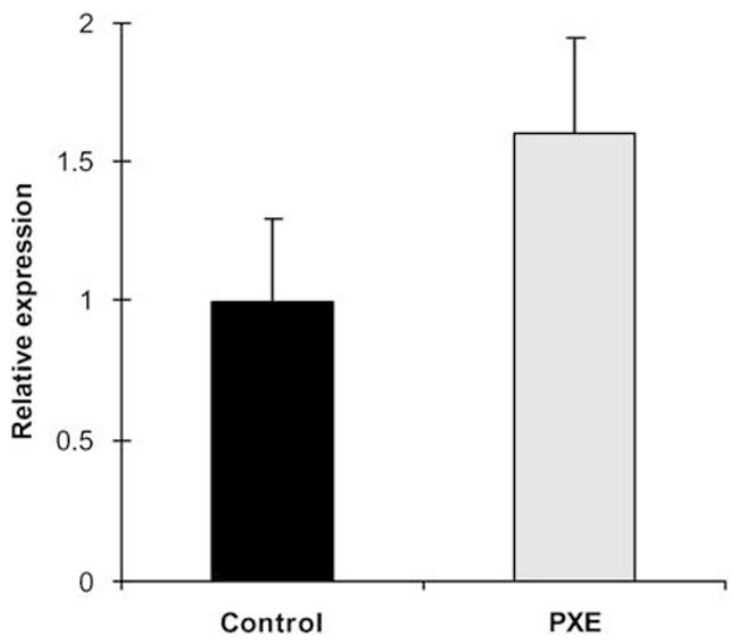

Figure 5 MGP mRNA expression in control and PXE fibroblasts assayed by RT-PCR. Differences between control and PXE cells were not significant.

serum of PXE patients, ${ }^{6}$ and the authors suggested that fetuin might have disappeared from the circulation by remaining entrapped within the calcium/phosphate mineral precipitates typical of PXE. ${ }^{6}$ Without excluding a similar possibility, data of the present study seem to suggest that the lower amount of circulating MGP in PXE patients may be related to reduced expression of MGP, and in particular of the active $\gamma$-carboxylated form of MGP by peripheral cells, rather than to its capture by mineralized elastic fibers.

a

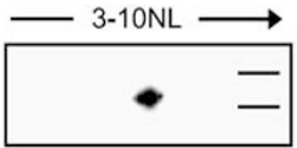

Actin Control

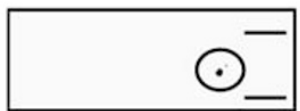

Glu-MGP Control

b

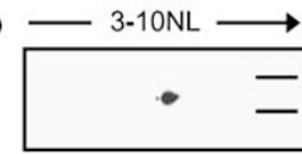

Actin Control

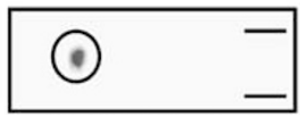

Gla-MGP Control

c
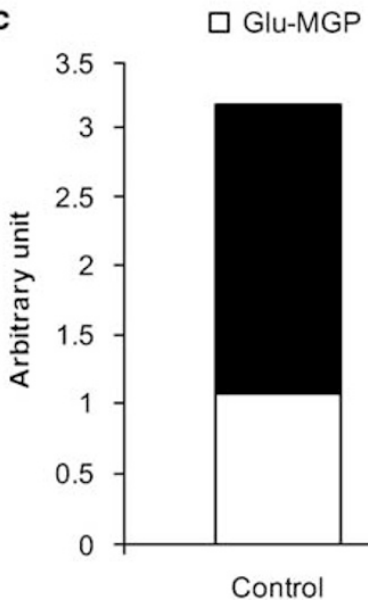

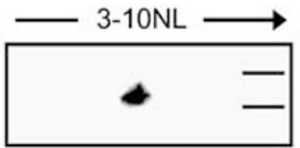

Actin PXE

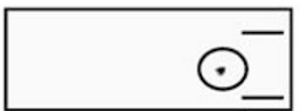

Glu-MGP PXE

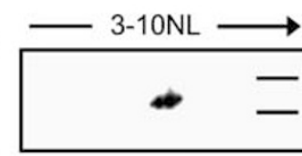

Actin PXE

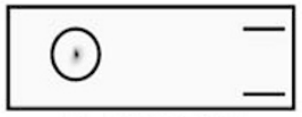

Gla-MGP PXE

- Gla-MGP

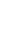

$50 \mathrm{kDa}$ $37 \mathrm{kDa}$

$15 \mathrm{kDa}$ $10 \mathrm{kDa}$

$50 \mathrm{kDa}$ $37 \mathrm{kDa}$

$15 \mathrm{kDa}$ $10 \mathrm{kDa}$
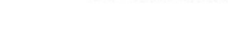

Figure 6 Noncarboxylated-MGP and $\gamma$-carboxylated MGP expressed by in vitro fibroblasts were assayed at protein level by western blot. Data were normalized to $\beta$-actin. PXE fibroblasts expressed 25\% less MGP compared to controls (a, b). In addition, both control and PXE cells produced similar amount of noncarboxylated MGP, whereas $\gamma$-carboxylated MGP was more than $30 \%$ higher in control compared to PXE fibroblasts (c).

Figure 4 Immunolocalization of glu- and Gla-MGP in calcified dermal elastic fibers in PXE patients. The polymorphous precipitates deforming elastic fibers (a, arrows) coexisted with areas of fine disperse calcification precipitates (a and $\mathbf{b}$, asterisk), which were very often separated from the surrounding

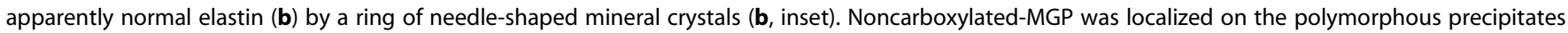

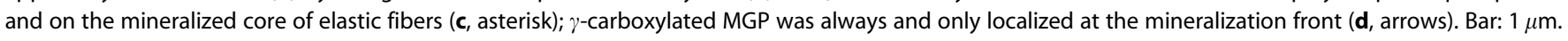



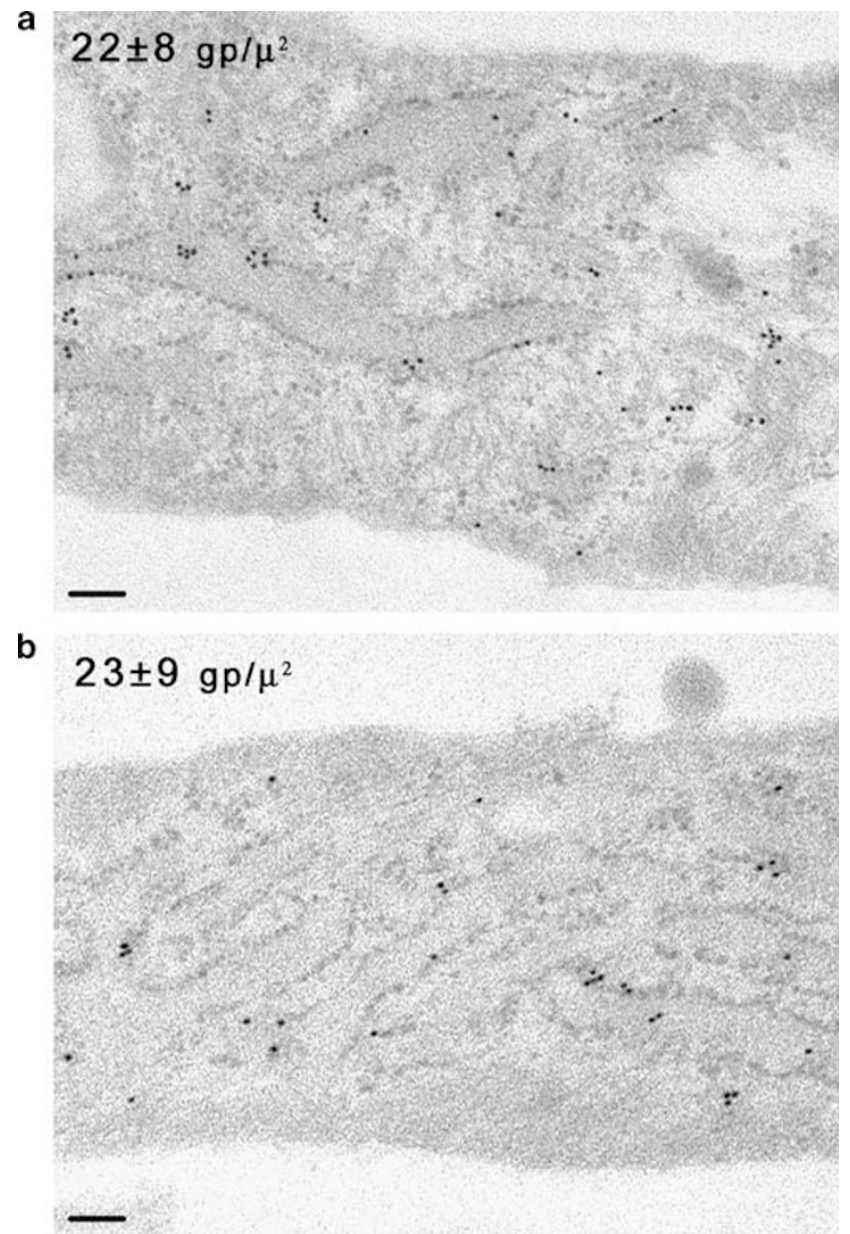

Figure 7 Immunolocalization of noncarboxylated MGP (Glu-MGP) on in vitro fibroblasts from control (a) and PXE patients (b). In both cases, MGP localized on membranes of the endoplasmic reticulum. The amount of noncarboxylated MGP, evaluated as number of gold particles (gp) per unit area, was similar in control (a) and PXE fibroblasts (b). Bar: $0.1 \mu \mathrm{m}$.

By immunoelectron microscopy, Glu-MGP was equally present within noncalcified elastic fibers of both controls and patients; by contrast, Gla-MGP was present in controls whereas it was almost absent from nonmineralized elastic fibers of patients. Similar findings were also found for dermal fibroblasts cultured in vitro where PXE fibroblasts appeared to be significantly less positive for Gla-MGP compared to controls. Therefore, the ratio of Gla-MGP to Glu-MGP would seem of paramount importance in understanding the occurrence of ectopic mineralization.

From these data it would seem that local cells, such as fibroblasts, play an important role in preventing dermal elastic fiber calcification. It has been repeatedly shown that MGP, although it is a circulating protein, acts as inhibitor of the extracellular matrix calcification in the vicinity of cells expressing the protein. ${ }^{12,34,37}$ Therefore, our findings that PXE fibroblasts express lower amount of the $\gamma$-carboxylated form of MGP compared to controls may suggest that calcification of elastic fibers, at least in the dermis of PXE
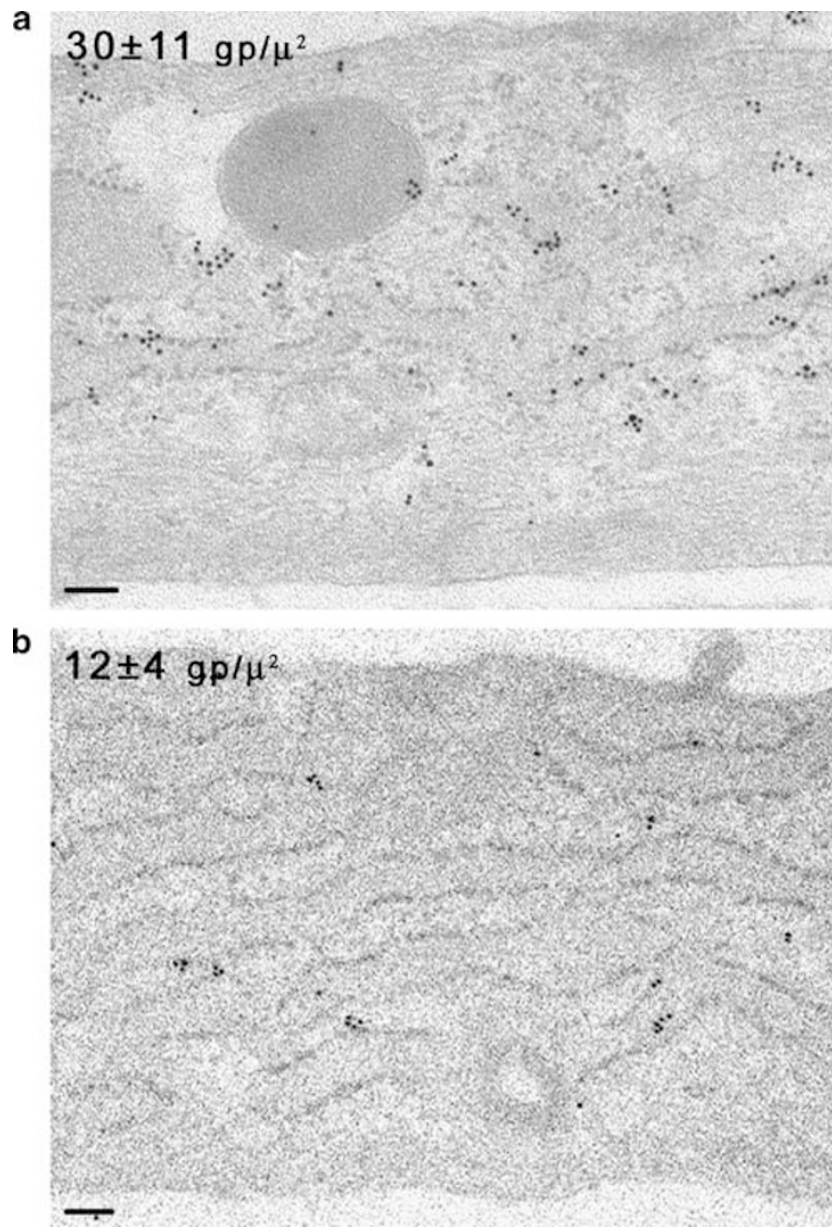

Figure 8 Immunolocalization of $\gamma$-carboxylated MGP (Gla-MGP) on in vitro fibroblasts from controls (a) and PXE patients (b). In both cases, MGP localized on membranes of the endoplasmic reticulum. The amount of $\gamma$-carboxylated MGP, evaluated as number of gold particles (gp) per unit area, was much higher in control $(\mathbf{a})$ than in PXE fibroblasts $(\mathbf{b})(P<0.001)$. Bar: $0.1 \mu \mathrm{m}$.

patients, might depend on local scarce availability of the active carboxylated form of MGP. ${ }^{26}$ This hypothesis is in agreement with data obtained on transgenic animals showing that local, and not systemic, expression of MGP inhibits extracellular matrix calcification, ${ }^{34}$ and with findings showing that only living smooth muscle cells producing MGP are able to prevent calcification of aortic rings in organ culture. ${ }^{37}$

How to reconcile ABCC6 mutations in PXE with impaired expression and maturation of MGP is an open question. In the absence of knowledge on the physiological role of the membrane transporter responsible for PXE, we approach the problem of clinical manifestations in PXE by trying to understand the mechanisms of elastic fiber calcification, to identify cells involved and to characterize alterations of connective tissue metabolism relevant for the progression of disease.

It has been repeatedly reported that fibroblasts from patients, despite their very low or absent expression of the 
PXE causative gene ${ }^{39}$ exhibit and maintain, at least up to the tenth passage in vitro, behavioral, ${ }^{29}$ biochemical, ${ }^{40,41}$ and degradation ${ }^{42}$ properties different from controls. Therefore, PXE fibroblasts seem to bear permanent metabolic alterations that are maintained when cultured in vitro and that, in vivo, could be responsible for local clinical manifestations.

We have recently reported that PXE fibroblasts in vitro suffer from a mild chronic oxidative stress with production of significantly higher amount of malondialdehyde compared to controls. ${ }^{43}$ Since malondialdehyde is the final product of phospholipid peroxidation induced by oxidative stress, the organization of cell membranes in PXE would be different from controls (unpublished data). This, in turn, may affect the activity of enzymes localized on membranes of the endoplasmic reticulum, such as the enzyme $\gamma$-carboxylase, ${ }^{44,45}$ whose activity is necessary for MGP $\gamma$-carboxylation. Therefore, disturbance of the $\gamma$-carboxylase system, however induced, might lead to deficient expression of active MGP. Very recently, skin and vessel alterations similar to those in PXE have been observed in patients suffering from vitamin K-dependent coagulation factor deficiency associated with mutations in genes coding for enzymes involved in the $\gamma$-carboxylation pathway and recycling. ${ }^{27}$ Therefore, maturation of MGP by the vitamin K-dependent $\gamma$-carboxylase, an endoplasmic reticulum enzyme, has fundamental importance in preventing extracellular matrix calcification and, in particular, calcification of dermal elastic fibers similar to those in PXE. ${ }^{27}$ PXE patients do not suffer from coagulation deficiency and those of the present study had normal levels of factors II and VII. Therefore, it is not that MGP deficiency in PXE patients may depend on alterations in the vitamin K-dependent $\gamma$-carboxylase system per se.

The present report indicates that elastic fiber calcification in PXE is associated with scarce expression and accumulation within elastic fibers of the mature $\gamma$-carboxylated form of MGP, an inhibitor of ectopic calcification in soft connective tissues. Moreover, since the reduced expression of the mature $\gamma$-carboxylated form of MGP by PXE dermal fibroblasts is associated with significant lower amount of circulating MGP in patients compared to controls, we suggest that fibroblasts may be, at least partially, responsible for the low level of circulating MGP. This is in agreement with recent observations that mature MGP is synthesized by cells in periphery, ${ }^{34}$ where it would exert local inhibition of ectopic calcification. ${ }^{12,34,37}$

In conclusion, impaired maturation of MGP would be part of the metabolic alterations of PXE fibroblasts and could play a relevant role in time-dependent stability of elastic fibers in PXE.

\section{ACKNOWLEDGEMENT}

We are grateful to members of PXE-Italia ONLUS for their help in donating samples, to PXE-International for the support, to Dr Marcello Pinti who supervised RT-PCR experiments, and to Professor Lionel Bercovitch for precious criticisms and help with the manuscript. Grants and support: MIUR
(2004064073-001); EC (LSHM-CT-2005-512117- GENESKIN); EC, LSHM-CT2005-018960-ELASTAGE)

1. Schinke $T$, McKee MD, Karsenty G. Extracellular matrix calcification: where is the action? Nat Genet 1999;21:150-151.

2. Denecke B, Graber S, Scafer C, et al. Tissue distribution and activity testing suggest a similar but not identical function of fetuin- $B$ and fetuin-A. Biochem J 2003;376:135-145.

3. Schafer $C$, Heiss A, Schwarz A, et al. The serum protein $\alpha 2$ HeremansSchmid glycoprotein/fetuin-A is a systemically acting inhibitor of ectopic calcification. J Clin Invest 2003;112:357-366.

4. Schinke T, Amendt C, Trindl A, et al. The serum protein $\alpha 2-\mathrm{HS}$ glycoprotein/fetuin inhibits apatite formation in vitro and in mineralizing calvaria cells. J Biol Chem 1996;271:20789-20796.

5. Heiss A, DuChesne A, Denecke D, et al. Structural basis of calcification inhibition by alpha-2-HS glycoprotein/fetuin-A. Formation of colloidal calciprotein particles. J Biol Chem 2003;278:13333-13341.

6. Hendig $D$, Schulz $V$, Arndt $M$, et al. Role of serum fetuin- $A$, a major inhibitor of systemic calcification, in pseudoxanthoma elasticum. Clin Chem 2006;52:227-234.

7. Danielsen L, Kobayasi T, Larsen HW, et al. Pseudoxanthoma elasticum. A clinico-pathological study. Acta Derm Venereol 1970;50:355-373.

8. Pasquali Ronchetti I, Volpin D, Baccarani Contri M, et al. Pseudoxanthoma elasticum: biochemical and ultrastructural study. Dermatologica 1981;163:307-326.

9. Gheduzzi D, Sammarco R, Quaglino D, et al. Extracutaneous ultrastructural alterations in pseudoxanthoma elasticum. Ultrastruct Pathol 2003;27:375-384.

10. Price PA, Williamson MK, Nguyen TMT, et al. Serum levels of the fetuin-mineral complex correlate with arterial calcification in the rat. J Biol Chem 2004;279:1594-1600.

11. Price PA, Williamson MK. Primary structure of bovine matrix Gla protein, a new vitamin K-dependent bone protein. J Biol Chem 1985;260:14971-14975.

12. Luo G, Ducy P, McKee MD, et al. Spontaneous calcification of arteries and cartilage in matrix gla protein. Nature 1997;386:78-81.

13. Munroe PB, Olgunturk RO, Fryns JP, et al. Mutations in the gene encoding the human matrix Gla protein cause Keutel syndrome. Nat Genet 1999;21:142-144.

14. Meier M, Weng LP, Alexandrakis E, et al. Tracheobronchial stenosis in Keutel syndrome. Eur Resp J 2001;17:566-569.

15. Fraser JD, Price PA. Lung, heart, and kidney express high levels of mRNA for the vitamin K-dependent matrix Gla protein: implications for the possible functions of matrix Gla protein and for the tissue distribution of the gamma-carboxylase. J Biol Chem 1988;263: 11033-11036.

16. Hale JE, Fraser JD, Price PA. The identification of matrix Gla protein in cartilage. J Biol Chem 1988;263:5820-5824.

17. Shanahan CM, Weissberg PL, Metcalfe JC. Isolation of gene markers of differentiated and proliferating vascular smooth muscle cells. Circ Res 1993;73:193-204.

18. Rannels SR, Cancela ML, Wolpert EB, et al. Matrix Gla protein gene expression in cultured type II pneumocytes. Am J Physiol 1993;265:L270-L278.

19. Mori $K$, Shioi $A$, Jono $S$, et al. Expression of matrix Gla protein (MGP) in an in vitro model of vascular calcification. FEBS Lett 1998;433:19-22.

20. Yagami K, Suh JY, Enomoto-Iwamoto M, et al. Matrix GLA protein is a developmental regulator of chondrocyte mineralization and, when constitutively expressed, blocks endochondral and intramembranous ossification in the limb. J Cell Biol 1999;147:1097-1108.

21. Howe AM, Webster WS. Warfarin exposure and calcification of the arterial system in the rat. Intern J Exp Path 2000;81:51-56.

22. Price PA, Faus SA, Williamson MK. Warfarin causes rapid calcification of the elastic lamellae in rat arteries and heart valves. Arterioscler Thromb Vasc Biol 1998;18:1400-1407.

23. Price PA, Faus SA, Williamson MK. Warfarin-induced artery calcification is accelerated by growth and vitamin D. Arterioscler Thromb Vasc Biol 2000:20:317-327.

24. Taybi $\mathrm{H}$, Capitanio MA. Tracheobronchial calcification: an observation in three children after mitral valve replacement and warfarin sodium therapy. Radiology 1990;176:728-730. 
25. Schori TR, Stungis GE. Long-term warfarin treatment may induce arterial calcification in humans: case report. Clin Invest Med 2004;27:107-109.

26. Spronk HM, Soute BA, Schurgers LJ, et al. Matrix Gla protein accumulates at the border of regions of calcification and normal tissue in the media of the arterial vessel wall. Biophys Biochim Res Commun 2001;289:485-490.

27. Vanakker O, Martin L, Gheduzzi D, et al. Pseudoxanthoma elasticumlike phenotype with cutis laxa and multiple coagulation factor deficiency represents a separate genetic entity. J Invest Dermatol 2007; 127:581-587.

28. Gheduzzi D, Guidetti R, Anzivino $C$, et al. ABCC6 mutations in Italian families affected by pseudoxanthoma elasticum (PXE). Hum Mutat 2004;24:438-439.

29. Quaglino D, Boraldi F, Barbieri D, et al. Abnormal phenotype of in vitro dermal fibroblasts from patients with pseudoxanthoma elasticum (PXE). Biochim Biophys Acta 2000;1501:51-62.

30. Livak $\mathrm{Kj}$, Schmittgen TD. Analysis of relative gene expression data using real-time quantitative PCR and the $2^{-\Delta \Delta C t}$ method. Methods 2001;25:402-408.

31. Baccarani Contri M, Boraldi F, Taparelli F, et al. Matrix proteins with high affinity for calcium ions are associated with mineralization within the elastic fibers of pseudoxanthoma elasticum dermis. Am J Pathol 1996;148:569-577.

32. Schurgers LJ, Teunissen KJF, Knapen MHJ, et al. Novel conformationspecific antibodies against matrix $\gamma$-carboxyglutamic acid (Gla) protein Undercarboxylated matrix Gla protein as marker for vascular calcification. Arterioscler Thromb Vasc Biol 2005;25:1629-1633.

33. Schurgers LJ, Teunissen KJF, Knapen MHJ, et al. Characteristics and performance of an immunosorbent assay for human matrix Gla-protein. Clin Chim Acta 2005;351:131-138.

34. Murshed M, Schinke T, McKee MD, et al. Extracellular matrix mineralization is regulated locally; different roles of two gla-containing proteins. J Cell Biol 2004;165:625-630.
35. Tamburro AM, Guantieri V, Daga-Gordini D, et al. Concentrationdependent conformational transition of alpha elastin in aqueous solution. J Biol Chem 1978;253:2893-2894.

36. Gordon SG, Subryan VL, Solomons CC, et al. In vitro uptake of calcium by dermis of patients with pseudoxanthoma elasticum. J Lab Clin Med 1975;86:638-643.

37. Price PA, Chan WS, Jolson DM, et al. The elastic lamellae of devitalized arteries calcify when incubated in serum: evidence for a serum calcification factor. Arterioscler Thromb Vasc Biol 2006;26: 1079-1085.

38. Luo G, D'Souza R, Hogue $D$, et al. The matrix gla protein gene is a marker of the chondrogenesis cell lineage during mouse development. J Bone Miner Res 1995;10:325-334.

39. Matsuzaki Y, Nakano A, Jiang QJ, et al. Tissue-specific expression of the ABCC6 gene. J Invest Dermatol 2005;125:900-905.

40. Passi A, Albertini R, Baccarani-Contri $M$, et al. Proteoglycan alterations in skin fibroblast cultures from patients affected with pseudoxanthoma elasticum. Cell Biochem Funct 1996;14:111-120.

41. Tiozzo-Costa R, Baccarani-Contri M, Cingi MR, et al. Pseudoxanthoma elasticum (PXE): ultrastructural and biochemical study on proteoglycan and proteoglycan-associated material produced by skin fibroblasts in vitro. Coll Rel Res 1988;8:49-64.

42. Quaglino D, Tiozzo R, Passi A, et al. Metalloproteases/antiproteinases imbalance in cultured dermal fibroblasts from pseudoxanthoma elasticum patients. Biochim Biophys Acta 2005;1741:42-47.

43. Pasquali Ronchetti I, Garcia-Fernandez MI, Boraldi F, et al. The occurrence of oxidative stress in fibroblasts from patients with pseudoxanthoma elasticum. Its role in the pathogenesis of clinical manifestations. J Pathol 2006;207:54-61.

44. Cain D, Hutson SM, Wallin R. Assembly of the warfarin-sensitive vitamin $\mathrm{K} 2$,3, epoxide reductase enzyme complex in endoplasmic reticulum membrane. J Cell Biol 1997;272:29068-29075.

45. Tie J, Wu SM, Jin D, et al. A topological study of the human $\gamma$-glutamyl carboxylase. Blood 2000;96:973-978. 